\title{
Acute treatment of myasthenia gravis with intranasal neostigmine: clinical and electromyographic evaluation
}

R Ricciardi, B Rossi, M Nicora, A Sghirlanzoni, A Muratorio

\begin{abstract}
The effectiveness of intranasal neostigmine (9.3-13.8 $\mathrm{mg}$ ) was tested in 20 subjects with myasthenia gravis, classified as Osserman grades $2 A$ and $2 B$. In all cases the drug produced significant clinical and electromyographic improvement. No side effects were reported during the treatment.
\end{abstract}

A new route of administration of anticholinesterase drugs in myasthenia gravis was tested by Dooley et al $^{1}$ in a patient with severe side effects from oral pyridostigmine. We used the nebulised form, which is likely to act principally at the cranial muscular level, resulting in improvements in facial, throat, and ocular weakness and the disappearance of the side effects. Given the high vascularity of the rhinopharynx, intranasal topical treatment could prove particularly suitable for patients whose intestinal absorption is erratic or where bulbar weakness hampers swallowing. The intranasal route avoids the hepatic first pass effect, and its pharmacokinetic profile for the small molecules is similar to the one shown by the intravenous route. ${ }^{2}$ In healthy volunteers the pharmacokinetic profile of neostigmine is similar via both routes. ${ }^{3}$

We examined the effectiveness of intranasal neostigmine in patients with myasthenia.

\section{Patients and methods}

We conducted a clinical and electromyographic evaluation of 20 patients ( 15 women and five men, aged 25 to 78 (mean 52) years) affected by myasthenia gravis type $2 A$ and $2 B^{4}$ and chronically treated with pyridostigmine bromide, in some cases with steroid or azathioprine or both. Patients gave informed consent. The evaluation was carried out in basal condition (five hours after the last oral dose of pyridostigmine) and 15 and 20 minutes after the intranasal administration of 2-3 puffs of watery solution of neostigmine methylsulfate $(6 \mathrm{~g} / 100 \mathrm{ml}(4.6 \mathrm{mg} /$ puff, Formenti Pharmaceutical Co.)). Clinical evaluation was based on a global muscle function score system $^{5}$ that provided a numerical score for muscular strength and endurance. Different grades of disability (ocular, generalised, bulbar, and respiratory) were observed. The final condition of the patient was assessed by the total sum of the scores calculated for each of the functions. Electromyographic assessment consisted of a repetitive sequence of $3 \mathrm{~Hz}$ stimuli applied to the axillary nerve at Erb's point at the junction between the edge of the sternocleiodomastoid and the clavicle. ${ }^{6}$ The deltoid muscle EMG activity was recorded by means of chlorinated silver-cup shaped electrodes. To prevent any artefact the patient's arm movement was restricted with elastic bands. A response was considered myasthenic when the fifth response decreased by over $10 \%$ with respect to the first one. ${ }^{7}$

The dose of neostigmine (number of puffs) used for the test was equivalent to the dose of pyridostigmine usually taken orally. One puff $(4.6 \mathrm{mg})$ of intranasal neostigmine was estimated to be equivalent to $20 \mathrm{mg}$ of oral pyridostigmine. This was verified in three patients by administering doses of intranasal neostigmine at one hour intervals starting with one spray and increasing each time by one until the clinical improvement in global muscle function equalled that obtained with $60 \mathrm{mg}$ oral pyridostigmine or $0.5 \mathrm{mg}$ intravenous neostigmine. Three sprays were found necessary for a maximal effect.

Data concerning the plasma levels of intranasal neostigmine were reported by Broggini et $a l,^{3}$ a duration of about three hours in the relevant therapeutic efficacy being observed. Analysis was undertaken with two tailed Wilcoxon signed rank and Student $t$ tests.

\section{Results and discussion}

All the patients showed a clear improvement of the neuromuscular fatiguability 15 minutes after intranasal neostigmine, as indicated by the drop in the clinical scores (table). After the intranasal neostigmine the response to the repetitive EMG stimulation test became normal in 17 patients, and showed a significant improvement in the other three.

The intranasal use of neostigmine in patients with myasthenia is of interest considering certain peculiar therapeutic aspects and the greater bioavailability with respect to the oral route. It can therefore be used for those patients needing rapid treatment who are unable or find it difficult to swallow. In $80 \%$ of cases of myasthenia gravis the pharyngo-laryngo-palatine muscles are involved, thus causing disphagia. Moreover, the chewing difficulty, which is often slight at onset becomes more evident with time. Patients can often take only liquid food or food that requires little chewing. Episodes of regurgitation of the liquid food through the 
Table Comparison of clinical variables, and EMG test before and after neostigmine treatment

\begin{tabular}{|c|c|c|c|c|c|c|c|c|}
\hline \multirow[b]{2}{*}{ Patients } & \multicolumn{4}{|c|}{ Basal values } & \multicolumn{4}{|c|}{ After neostigmine } \\
\hline & Ocular & General & Bulbar & EMG test & Ocular & General & Bulbar & EMG test \\
\hline 1 & 3 & 150 & 4000 & 32 & 3 & 100 & 2000 & 0 \\
\hline 2 & 5 & 110 & 0 & 23 & 3 & 60 & 0 & 5 \\
\hline 3 & 3 & 150 & 0 & 26 & 1 & 100 & 0 & 3 \\
\hline 4 & 0 & 100 & 0 & 29 & 0 & 40 & 0 & 14 \\
\hline 5 & 2 & 70 & 1000 & 29 & 0 & 30 & 0 & 2 \\
\hline 6 & 0 & 130 & 0 & 37 & 0 & 70 & 0 & 9 \\
\hline 7 & 2 & 150 & 0 & 12 & 1 & 70 & 0 & 0 \\
\hline 8 & 3 & 140 & 1000 & 53 & 2 & 70 & 0 & 32 \\
\hline 9 & 0 & 30 & 0 & 16 & 0 & 0 & 0 & 7 \\
\hline 10 & 1 & 10 & 1000 & 31 & 0 & 0 & 0 & 18 \\
\hline 11 & 0 & 100 & 0 & 25 & 0 & 40 & 0 & 4 \\
\hline 12 & 7 & 140 & 1000 & 30 & 4 & 10 & 0 & 5 \\
\hline 13 & 0 & 82 & 0 & 17 & 1 & 30 & 0 & 0 \\
\hline 14 & 7 & 140 & 4000 & 62 & 3 & 130 & 2000 & 6 \\
\hline 15 & 0 & 50 & 0 & 23 & 0 & 0 & 0 & 1 \\
\hline 16 & 0 & 84 & 0 & 15 & 1 & 50 & 0 & 0 \\
\hline 17 & 3 & 140 & 0 & 26 & 2 & 60 & 0 & 2 \\
\hline 18 & 2 & 120 & 4000 & 16 & 1 & 60 & 2000 & 1 \\
\hline 19 & 1 & 160 & 3000 & 13 & 1 & 120 & 1000 & 0 \\
\hline 20 & 3 & 130 & 2000 & 14 & 0 & 50 & 0 & 3 \\
\hline
\end{tabular}

Clinical evaluations reveal significant differences: ocular $\mathrm{z}=2.67, \mathrm{p}<0.01$; general $\mathrm{z}=3.9, \mathrm{p}<0.001 ;$ bulbar $\mathrm{z}=2.1, \mathrm{p}<0.05$. EMG values express \% decrement in amplitude of fifth motor response with respect to first, during a $3 \mathrm{~Hz}$ stimuli sequence of axillary nerve, recording from deltoid muscle. There was a significant improvement after neostigmine $(t=8.98, p<0.001)$.

nose, a secondary symptom when the muscle of the soft palate or that of the upper oesophagus is involved, are common. These patients may find it impossible even to swallow a tablet.

A long term anticholinesterase treatment through the parenteral route is troublesome and dangerous, as patients are exposed to the risk of frequent cholinergic crises. An alternative route of treatment is highly desirable, especially in patients with a rapid progression of bulbar symptoms. In our study, the clinical variables were analysed with the functional rating scale proposed by Mantegazza et al. ${ }^{5}$ This quantifies the weakness through a single number, which is then used to infer rapidly the involvement of each group of muscles, providing a differential reading of the units in tens and thousands that make up the total figure. A considerable reduction in the neuromuscular fatiguability of the tested muscle groups was found for almost all the subjects after intranasal neostigmine. No improvement was seen in only two patients (cases 1 and 19), who had resistant oculomotor disorders and showed no reaction to standard anticholinesterase treatment.

The electromyographic tests confirmed these clinical data. Intranasal neostigmine brings about a rapid removal of the myasthenic neuromuscular block, results being comparable with those obtained with intravenous edrophonium chloride, even if the latency was longer, with a maximum effect in about 15 minutes. The effectiveness shown by intranasal neostigmine rules out the assumption that it may only act locally, on the oropharyngeal and ocular disorders, as assumed by Dooley et al. ${ }^{1}$ Indeed they noticed that when the nebulised pyridostigmine powder
(80 mg) dissolved in $2 \mathrm{ml}$ of sterile water was administered by an aerosol mask covering the mouth and nose, after isolating the eyes with goggles, the beneficial effect disappeared. This led them to conclude that the adsorption would take place through the conjunctiva. The results of our study suggest that neostigmine is absorbed through the nasal mucosa and enters the systemic circulation. The intranasal delivery of the drug partially bypasses the liver metabolism, ${ }^{8}$ which is responsible for the low bioavailability of oral neostigmine (1-2\%). The administration of intranasal antiAChE may be suitable when patients show irregular absorption of oral doses-or when they suffer from serious bulbar problems. During the trial no unexpected local or general symptoms were observed. Good tolerance and compliance of this route has been confirmed with medium term treatment. ${ }^{9}$

1 Dooley JM, Goulden FJ, Gibson EJ, Brown BJ. Topical therapy for oropharingeal symptoms of myasthenia gravis. Ann Neurol 1986;19:192-4.

2 Hersey SJ, Jackson RT. Effects of bile salts on nasal permeability in vitro. J Pharm Sci 1987;76(120):876-9.

3 Broggini M, Benvenuti C, Bottà V, Fossati A, Valenti M. Bioavailability of intranasal neostigmine. Meth Find Exptl Clin Pharmac (in press).

4 Osserman KE, Genkins G. Studies in myasthenia gravis. Review of a 20 years experience in over 1200 patients. Mount Sinai J Med 1971;38:497.

5 Mantegazza R, Antozzi C, Pelucchetti D, Sghirlanzoni A, Cornelio F. Azathioprine as a single drug or in combination with steroids in the treatment of myasthenia gravis. $J$ Neurol 1988;235:449-53.

6 Odzemir C, Young RR. Electrical testing in myasthenia gravis. Ann N Y Acad Sci 1971;183:207-302.

7 Slomic A, Rosenfalck A, Buchthal F. Electrical and mechanical responses of normal and myasthenic muscle. Brain Res 1968;10:1-78.

8 Somani SM, Chan K, Dehghan A, Calvey TN. Kinetics and metabolism of intramuscular neostigmine in myasthenia metabolism of intramuscular neostigmine

9 Sghirlanzoni A, Cosi V, Lombardi M, Nicora M, Pareyson D, Ricciardi R. Treatment of myasthenia gravis with intranasal neostigmine. Neurology 1989;37(suppl):15. 